\title{
A MOBILE SEISMOGRAPH ARRAY
}

\author{
By Francis E. Lehner and Frank Press
}

\begin{abstract}
A movable array composed of Ranger type seismometers, 60-day film recorders and 7-day magnetic tape recorders housed in compact trailers, has been developed. The array is useful for research requiring frequent instrument relocation such as $P$-delay, micro-seismicity, aftershock and signal-to-noise ratio studies.

The array unit combines the functions found in conventional fixed stations with a high degree of mobility. Conveniences such as solid state amplifiers, radio and clock circuitry, internal calibration, and minimum installation time are special features.

With the battery supply provided, a one week period of unattended film and tape recording is possible. With commercial power, the instruments can operate unattended for up to sixty days.

Useful magnification up to several million is available, depending on the frequency band selected.
\end{abstract}

\section{InTRODUCTION}

The advantages of seismic arrays are being increasingly appreciated by the seismological community. Signal-to-noise improvement with arrays is receiving special attention at this time. Other uses of arrays have been recognized and applied. One example is precision hypocenter location and determination of source mechanism for micro-earthquakes within the area covered by the array. Another example is the use of $P$-delays at elements of the array to determine structural features of the crust and mantle. The variation of magnitude correction with geology is a subject of interest, not only as a tool for finding anomalous structures, but also for finding sites for sensitive stations. Arrays have been used to study properties of microseisms, particularly with reference to direction of approach and velocity of propagation. Phase velocity of surface waves has been found using array data.

The augmented advantages of an array which is made mobile without sacrificing sensitivity and reliability are obvious. Such an array has been designed for special application to problems of micro-seismicity of active faults, regional $P$-delay reconnaissance, magnitude correction variations, and higher mode phase velocity studies. In order to attack these diverse problems, flexibility of response and sensitivity was designed into the system. Eight elements have been built initially; the first application of the array is to the problem of micro-seismicity of the San Andreas fault.

The plan is to locate the array in selected regions along the fault for periods of several months and gauge the seismic release occurring in the magnitude range around zero. The first installation is shown on the map of Figure 1. Recordings by several of the array units of a magnitude -0.7 event are shown in Figure 2. 


\section{Description of the Array Unit}

Instrumentation of the array unit includes the usual essentials of a seismograph station; namely, power supply, drive, time reference, seismometer, and recorders. Equipment was chosen or designed with a view to reliability and limited power consumption, and is housed in a specially built trailer having body dimensions of $4 \times 4 \times 6 \mathrm{ft}$. The trailer is divided into three compartments; the front section houses the control equipment, internal battery and a magnetic tape recorder, the center space contains a photographic recorder, and the last section serves as a dark entry

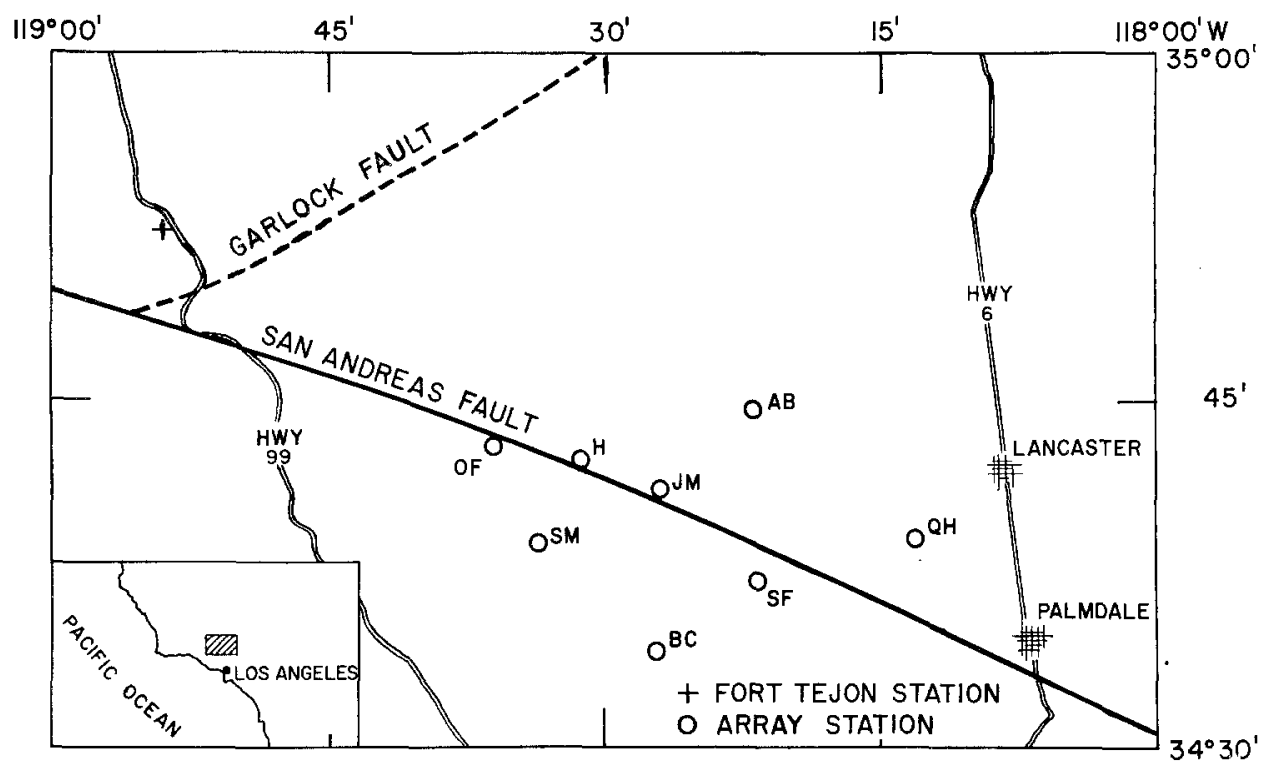

FIG. 1. Map of the initial array.

to the center section. The seismometer input amplifier, filters and test circuit panel are also mounted in the last section. The entry is fitted with a drop-down floor surrounded by a light-tight 'boot' providing convenient shelter while servicing the photographic recorder. Both the entry and the recorder chamber are fitted with safelights, and the latter with photosupply storage and other facilities adequate for installation of conventional recorders as well as the specially designed film unit.

One 24 volt battery housed internally provides 48 hour stand-by power. This is used when commercial power is available for float charging, or to operate the unit on short field trips away from power line connection. For longer periods of remote field operation, auxiliary batteries capable of operating the unit for a period in excess of one week can be installed in compartments external of the main body. Normal power requirement for all continuously operating components is approximately 30 watts. Views of the unit and a block diagram are shown in Figures 3, 4, and 5 .

In order from the bottom to the top of the control equipment rack (Figure 3) are the battery charger, time program panel, precise-frequency power supply, tape recorder input amplifier and control panel, and, at the top, the WWV time signal receiver. 


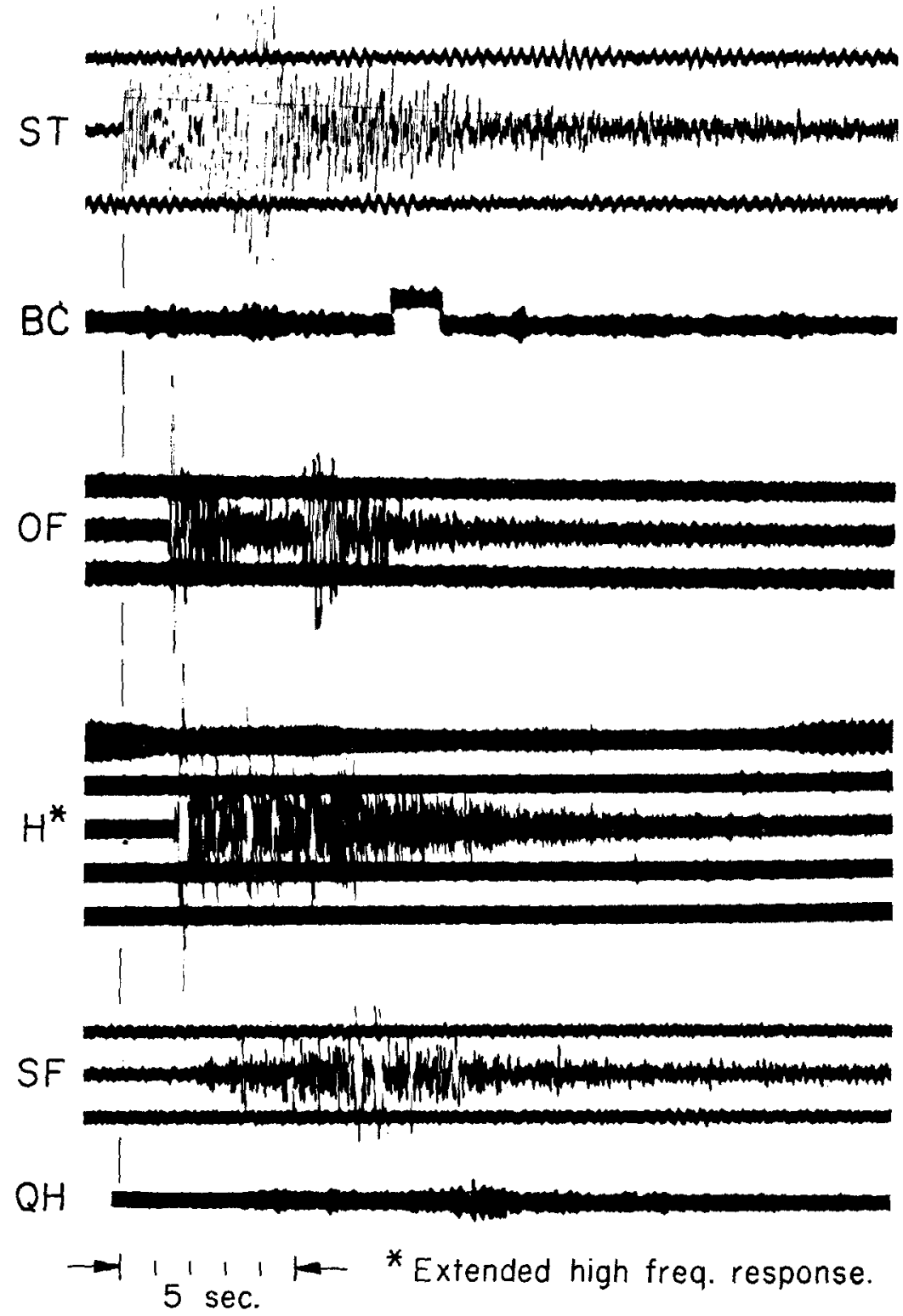

Fra. 2. Recording of a magnitude -0.7 event by six units.

The battery charger is voltage regulated and temperature compensated to provide optimum battery condition over a wide range of power line voltages and ambient temperatures. Correct charge rate is automatically maintained by referencing the firing angle of silicon controlled-rectifiers to the sensed battery voltage. The output is partially filtered; the instrumentation can operate directly from this supply without a battery connection, if necessary.

Clock marks are provided to the recorders once per minute and once per hour from the time program panel. A synchronous motor powered by the precise fre- 
quency power source drives a minute marking cam switch as well as the radio program time switch. Relation of the clock marks to G. C. T. is by comparison with radio time signals superimposed on, or in parallel with, the seismic data; radio may be programmed for seven minutes overlapping the last five minutes of any hour, to receive a full WWV period. Provision is made for direct recording of the rectified audio signal, or by actuation of a reed relay.

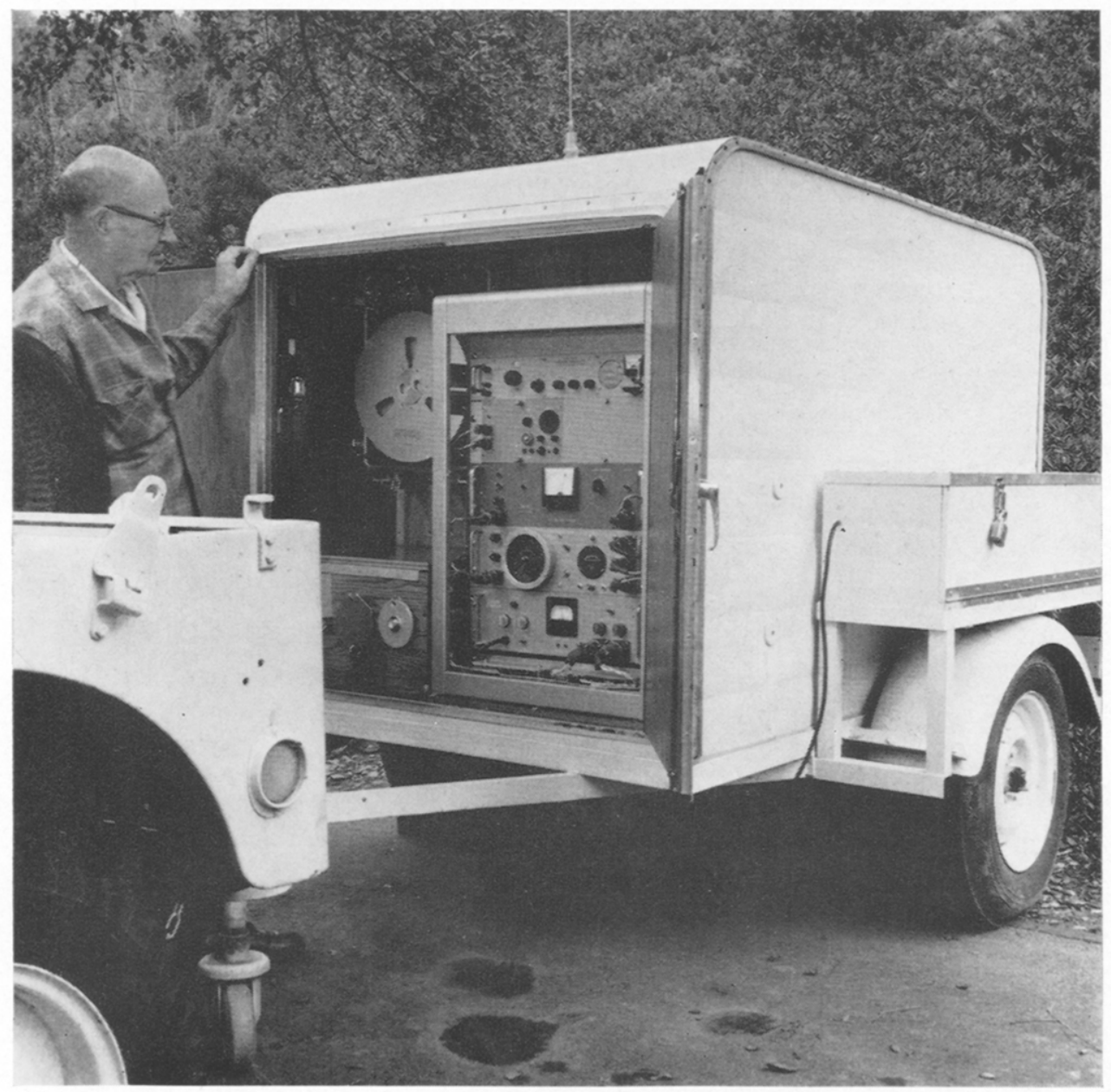

FIG. 3. View of the trailer showing control equipment and tape recorder.

A Tracor, Inc. fork-controlled inverter provides 110 volt 60 cps power with a 30 v.a. capability and a stability specification of 5 parts in 10 million per month. The photographic recorder drive motor, the radio program and time marking unit motor and the radio receiver are operated from this supply. While it is convenient to use a regulating step-down transformer to power the photographic recorder lamp from the inverter output, this is considerably more wasteful of power than the DC-DC converter and regulator designed for the lamp source. 


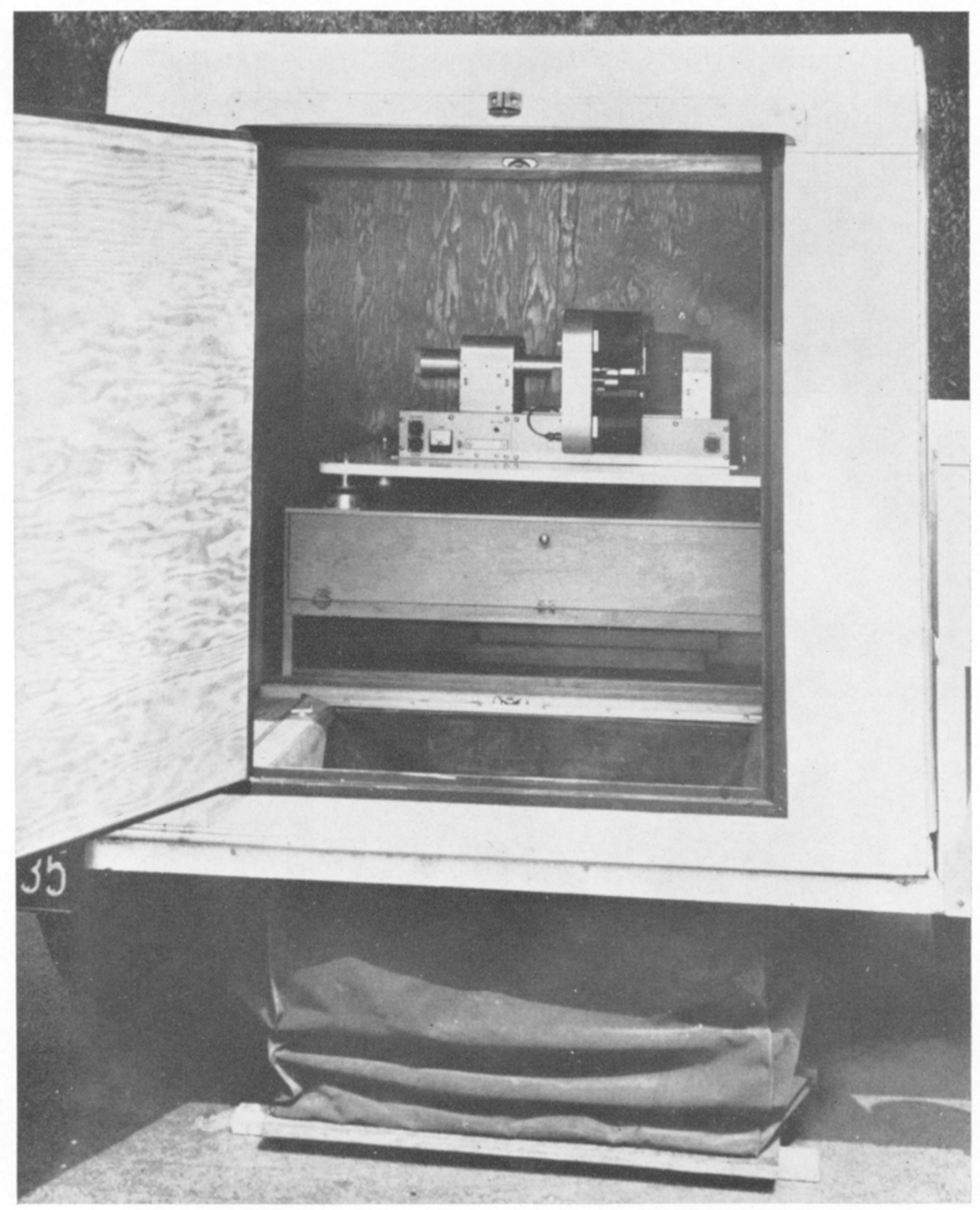

Fig. 4. Photo recording compartment with Long Term Recorder in place.

The Specific Products type WVTR radio is used for time signal reception. This is a transistorized receiver normally arranged to receive WWV transmissions on 2.5, $5,10,15,20$, and $25 \mathrm{mc}$. For the array units, the $25 \mathrm{mc}$ tuning elements have been replaced with $10 \mathrm{me}$ components and a proper oscillator crystal for reception of $9,277.5 \mathrm{kc}$; the channel is tuned-down to this frequency to receive Naval time signals from NPG at Mare Island, California. The latter are keyed CW; to make 
them audible, a crystal controlled beat-frequency oscillator has been added to the set. The radio may be operated on either 12 volts $\mathrm{DC}$ or 115 volts $60 \mathrm{cps} \mathrm{AC}$. Power consumption is approximately 2 watts. Reception has been excellent with an 8 ' whip antenna atop the trailer.

When in 'storage' at the Laboratory, the charger, inverter, time panel, and radio are kept in operation; there is no need to discontinue any of these functions during transportation. This eliminates 'settling-in' time of the clock and facilitates set-up in the field; in most cases, installation consists only of locating and approximately leveling the trailer, connecting and burying the seismometer, turning on of the amplifiers and recorders and setting the magnification level. These chores rarely consume more than 20 to 30 minutes.

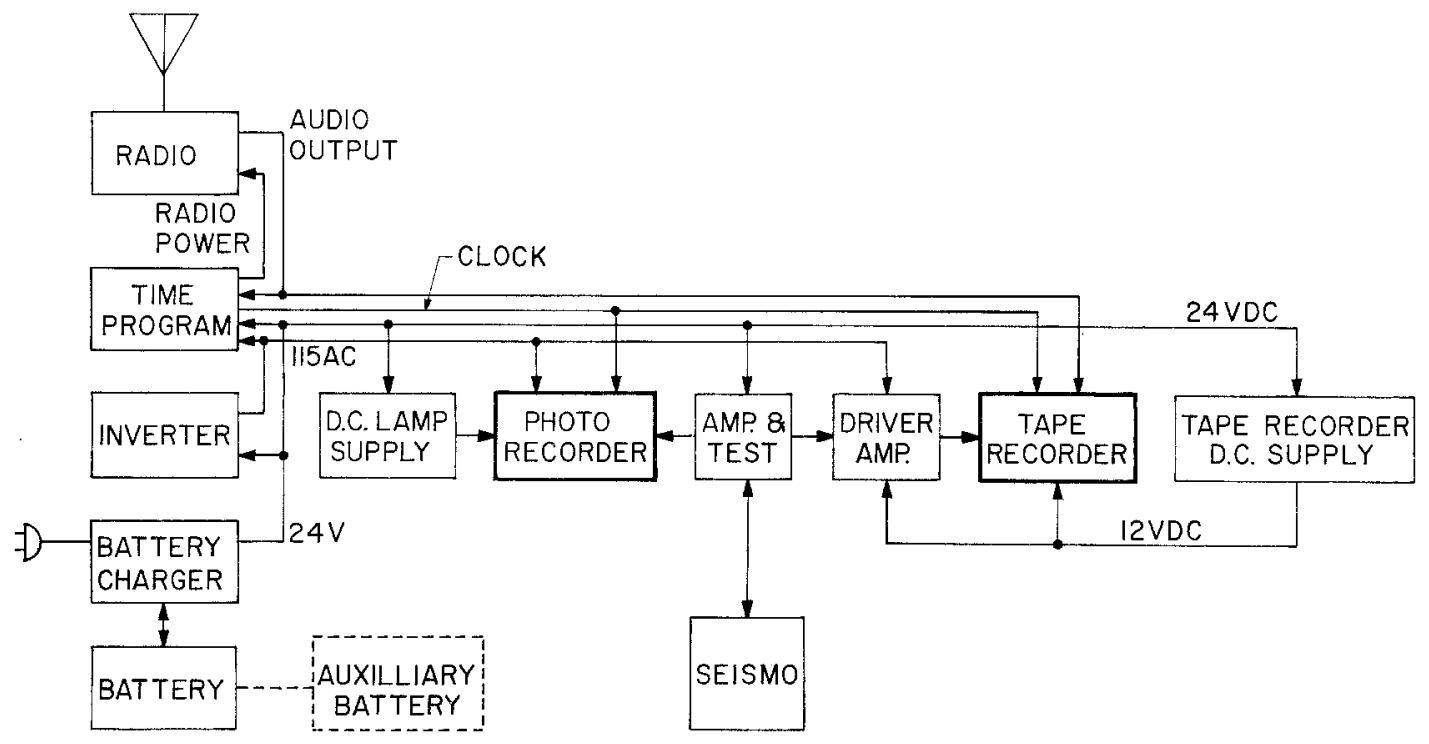

FIG. 5. Block diagram of the mobile seismograph system.

Seismic signal instrumentation. The seismometer is a modification of the Ranger lunar instrument developed at the Seismological Laboratory for the National Aeronautics and Space Administration. The suspended mass is $1.75 \mathrm{~kg}$; and the normal range of period adjustment is from 1 to 3 seconds, but in special instances has been extended to as long as 6 seconds. Output transducer coil resistance has been made $50 \mathrm{ohms}$ so that efficient direct coupling, as well as an amplified connection, can be made to the photographic recorder galvanometer. When the tape recorder is operating, the amplified connection must be used. In this situation, the galvanometer amplifier is followed by a second amplifier to increase the signal level to a value compatible with the input requirements of the tape recorder. Included with the second amplifier is a level indicator and gain adjustment for setting the microseism level with reference to the recorder noise threshold. Photographic recorder magnification is controlled with a $50 \mathrm{ohm}$ T-pad attenuator between the amplifier and the galvanometer, or, in the 'direct' connection, between seismometer and galvanometer. 
High frequency response is limited primarily by the galvanometer-seismometer characteristics. While the longer period response is ultimately limited by the output transformer associated with the amplifier, this may be cut further by insertion of one of several filters selectable by switching. The various characteristics as determined by shake table testing are shown in Figure 6; these are considered adequate for the present studies, but may easily be modified for other projects. The magnifications shown are based on use of a $15 \times$ projector for record reading, and are the values for which the system noise is approximately 3 per cent (peak-to-

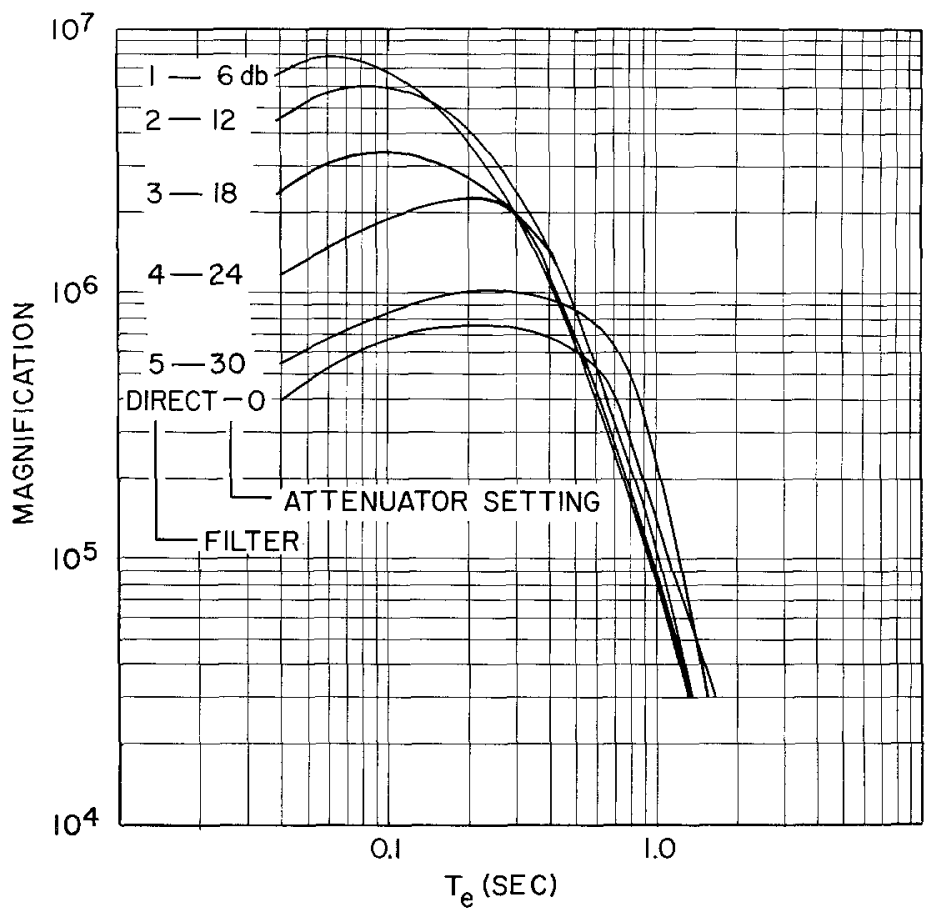

FrG. 6. Response curves with various filters and $T_{0}=1$.

peak) of the trace spacing. Figure 7 shows a simplified circuit of the amplifier and filter section, which includes provision for application of test deflection currents to the calibration coil in the seismometer. The amplifier is a modified United ElectroDynamics type 230729, and the associated galvanometer is a Geotechnical Corporation type $4100-23$, having a period of 0.2 seconds.

Considerable increase in magnification can be achieved by using a seismometer coil which matches the amplifier input resistance. This might be particularly desirable for work in which a shorter period, less sensitive, galvanometer is substituted to extend the high frequency response of the system.

For long period registration, the transformer must be replaced by coupling capable of passing low frequency signals. This might be an emitter follower stage to match the amplifier to the galvanometer, preceded by long period capacity coupling to eliminate any DC component existing in the amplifier output, and also to shape the system response. 
The magnetic tape recorder is a Precision Instrument, Model 5100. This is a four track FM unit (convertible to 7 track) operating at a tape speed of $.093^{\prime \prime}$ per second with a carrier center frequency of $84.4 \mathrm{cps}$. Frequency response and dynamic range are specified by the manufacturer as DC to $17 \mathrm{cps}$ and $42 \mathrm{db}$, respectively. This instrument is capable of recording for one week on a single reel of tape. Power requirement is approximately 7 watts at 12 volts DC. Since the trailer supply is 24 volts, a DC-DC converter similar to the lamp supply converter will be used to efficiently drop and regulate the voltage. No precise alternating current is required for the tape recorder; its drive is a servo-controlled DC motor which can tolerate

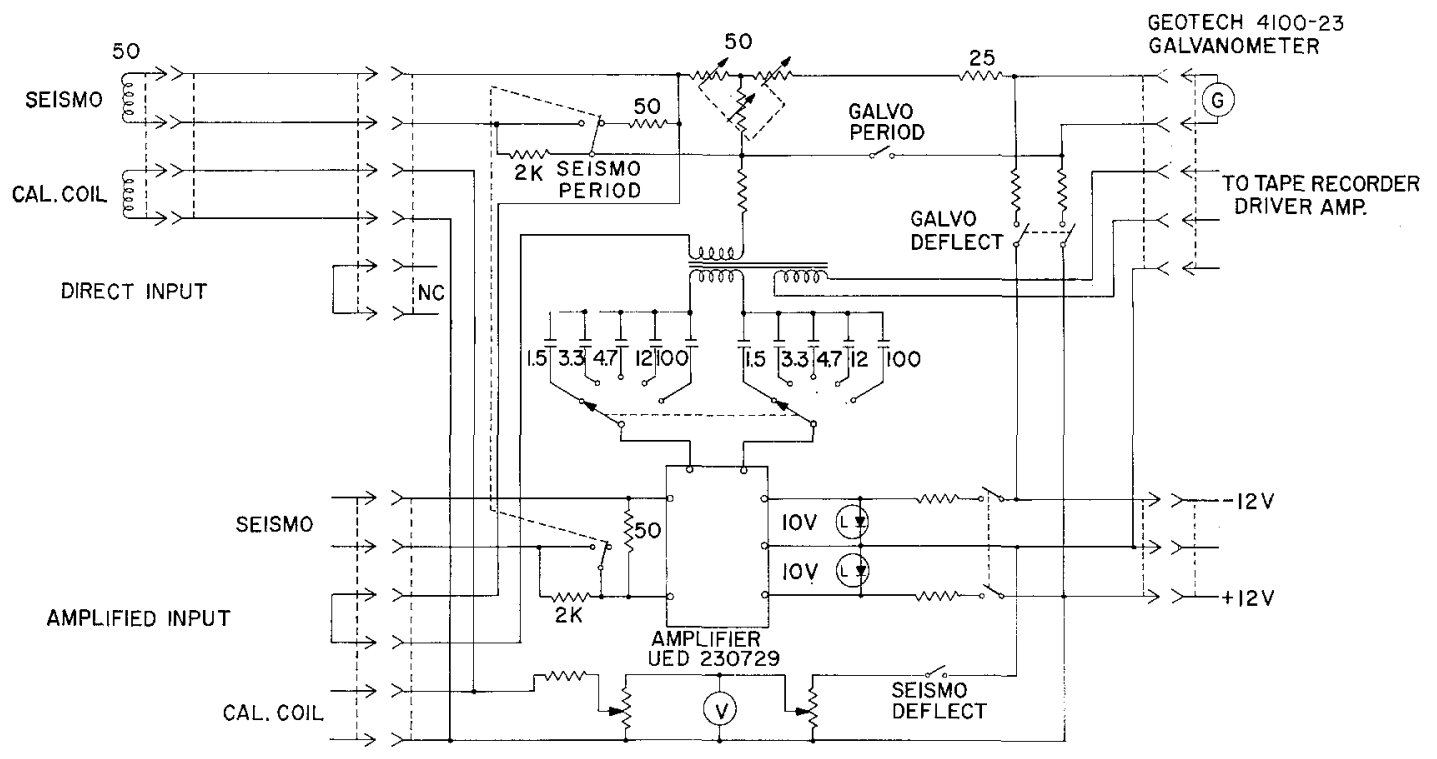

FIg. 7. Simplified amplifier and filter circuit.

considerable supply variation. The tape records will be used primarily for computer analysis of the data.

For visual registration, a special photographic recorder has been developed. This is shown in Figure 4 housed in the rear compartment. It is capable of writing more than fifty 48 -trace records of $450 \mathrm{~mm}$ length from a $100 \mathrm{ft}$. supply roll of $70 \mathrm{~mm}$ perforated motion picture film. Time duration of each record may be chosen from a few hours to many days by selecting a drive motor of the proper speed, and the device automatically changes to an unexposed section of film at the completion of a 48 -trace record. When operated so as to change each 24 hours, for 50 day recording capability, the recording speed is $\frac{1}{4} \mathrm{~mm}$ per second; this scale is comparable to that of the $35 \mathrm{~mm}$ film recorders on the market which write a 24 -trace record $900 \mathrm{~mm}$ in length. Exposed film accumulates in a receiver magazine and may be removed as convenient, such as at times when the trailers are visited for battery replacement.

In brief, the film recorder functions as follows:

From the supply magazine, the film passes about a transparent drum to which it is held in intimate contact during the recording period. Within the drum is a rotating 
optical system which, through the galvanometer mirror, imposes the registering image on the inner surface of the film. The film advance and drum assembly constitutes a carriage which progresses relative to the optical system, causing the image to expose a helical path on the emulsion side of the film. On completion of 48 revolutions ( $48 \mathrm{~mm}$ translation) the carriage returns to its starting position, the film is freed of the drum and is advanced by one increment, and is then re-clamped; these functions require about 30 sec. During the changing process, the rotating system continues to turn so that time relationship on all records is maintained. The transparent drum is bearing mounted so that it may be 'free-wheel' to prevent film seizure.

With Eastman blue-base sound recording film No. SP521, code 5469, lamp life is expected to be in excess of six months. An accessory unit containing several lamps which will change automatically on burn-out is being designed.

The recorder operates on 12 or 24 volts DC, and the drive motor supply (currently $110 \mathrm{~V} 60 \mathrm{cps}$ ). Power consumption is 6 watts continuously with an additional 3 watt requirement for approximately 30 seconds during the changing cycle.

\section{ACKNOWLEDGMENT}

This researeh was supported by the Advanced Research Projects Agency and was monitored by the Air Force Office of Scientific Research under Contract AF-49(638)-1337.

Designs of some of the equipment units, modification of others, and many useful suggestions were contributed by members of the Seismological Laboratory staff. Particular credit is due Mr. Nat Motta, Mr. Wayne Miller, and Mr. Witold Krynicki.

We wish to thank the U.S. Forestry Service, the Los Angeles Department of Water and Power, the Brigade Trails Camping Association, Mr. Harry Hauser, Mr. and Mrs. Jerry Miller, the Sawmill Ranch and Munz Ranch, for cooperation in situating the initial array.

Division of Geological Sciences

California Institute of Technology

Pasadena, California

Manuseript received December 15, 1965. 